\title{
PENENTUAN MUSIM TANAM PADI SAWAH MENGGUNAKAN DATA TIME SERIES CURAH HUJAN DI DAS LIMBOTO BONE BOLANGO
}

\section{Determining the Paddy Growing Season Using Time Series Data on Precipitation in the Limboto Bone Bolango Watershed}

\author{
Romansah Wumu $^{1 *}$, F.V. Astrolabe Sian Prasetya ${ }^{1}$ \\ ${ }^{1}$ Politeknik Pertanian Negeri Samarinda, Kampus Gunung Panjang, Jl. Samratulangi, \\ Samarinda, Indonesia \\ *romansah@politanisamarinda.ac.id
}

\begin{abstract}
Paddy is a staple food for most Indonesian people. A number of efforts were made to maintain the availability of paddy in the country. One of these efforts is to determine the beginning of the paddy planting season, especially lowland paddy in order to get maximum results and minimize crop failure. This study aims to determine the beginning of the growing season in the Limboto Bone Bolango watershed area. The beginning of the rainy season is the best time to be the beginning of the paddy planting season which requires sufficient irrigation in the vegetative phase. The data used in this study is rainfall time series data which is processed from TRMM 3B43 data: Monthly Precipitation Estimates (TRMM/3B43V7) and ERA5-Land monthly averaged - ECMWF climate reanalysis (ECMWF/ERA5_LAND/MONTHLY). Based on the time series data, the beginning of the rainy season is in February $(\overline{D O Y}>60)$ and October (DOY > 273). Based on this, it is expected that farmers in the Limboto Bone Bolango watershed can start the planting season in February and October.
\end{abstract}

Keywords : Growing Season, Irrigation, Rainfall, Rice, Watershed

\section{PENDAHULUAN}

Masyarakat Indonesia sebagian besar menjadikan Nasi sebagai bahan makanan pokok. Sejumlah kebijakan dibuat dan dilakukan pemerintah untuk meningkatkan ketahanan pangan khususnya padi. Penyesuaian waktu tanam merupakan upaya dengan biaya yang paling efisien untuk meningkatkan produktivitas, menstabilkan, bahkan meningkatkan ketahanan pangan (Surmaini et al. 2020).

Sejumlah penelitian telah dilakukan untuk mengetahui waktu tanam padi. Penelitian yang dilakukan Surmaini menunjukkan bahwa prediksi curah hujan musim dengan lead time 6-9 bulan menggunakan metode downscaling dengan dua tahap analog dapat memperpanjang lag prediksi 2 bulan sebelum tanam sehingga dapat digunakan untuk peringatan dini(Surmaini et al. 2020). Penelitian lain tentang penentuan waktu tanam dan kebutuhan air tanaman padi, jagung, kedelai dan bawang merah di Provinsi Jawa Barat dan Nusa Tenggara Timur menunjukkan waktu tanam yang lebih Provinsi Jawa Barat lebih lama karena memiliki bulan basah $>7$ bulan dibandingkan Provinsi Nusa Tenggara Timur yang beriklim kering (bulan basah $<7$ bulan) (Hariyanti et al. 2019). Hasil penelitian Balai Penelitian Agroklimat dan Hidrologi menyatakan kriteria umum untuk menentukan awal musim tanam padi di Indonesia adalah pada awal musim hujan dengan curah hujan $>50 \mathrm{~mm}$ dalam 3 dasararian berturut-turut (Surmaini and Syahbuddin 2016). Penelitian lain yang dilakukan oleh Jayanti dan Mowidu yang bertujuan untuk membangkitkan data curah hujan, juga menganalisis neraca air untuk menentukan masa tanam yang tepat diperoleh masa tanam padi di Desa Silanca, Kecamatan Lage Tahun 2015 yaitu bulan Januari- April, Februari-Mei, Maret-Juni, April-Juli, Mei-Agustus, September-Desember, Oktober- Januari, November-Februari, dan DesemberMaret(Jayanti and Mowidu 2014). Hasil- 
hasil penelitian diatas menunjukkan penentuan awal musim tanam padi Sejumlah penelitian mengenai data curah hujan dari data citra satelit juga telah dilakukan oleh para peneliti. Penelitian yang dilakukan oleh Dasanto tentang evaluasi curah hujan trmm menggunakan pendekatan koreksi bias statistic menunjukkan pola curah hujan dari data TRMM yang telah dikoreksi adalah mirip dengan besar yang berbeda (Dasanto et al. 2014). Penelitian yang dilakukan oleh Syaifullah mengenai validasi data TRMM terhadap data curah hujan aktual di tiga DAS di Indonesia menunjukkan menunjukkan data TRMM Jaxa lebih mendekati data pengamatan dibandingkan dengan TRMM NASA(Syaifullah 2014). Penelitian lain yang dilakukan oleh Gunawan menunjukkan korelasi antara data curah hujan TRMM dan data pengamatan lapangan yaitu antara 0.7-0.9, sehingga memungkinkan untuk mengisi kekosongan data curah hujan lapangan(Gunawan 2014). Penelitian lain yang dilakukan oleh Kurnia Performa Koreksi Bias Prakiraan Curah Hujan menggunakan data ECMWF menunjukkan prakiraan ECMWF system 4 setelah di koreksi bias menggunakan Linear Scaling (LS) dan Quantile Mapping (QM ) memiliki nilai yang mendekati nilai observasinya namun dari kedua metode bias tersebut, metode LS lebih memiliki performa paling

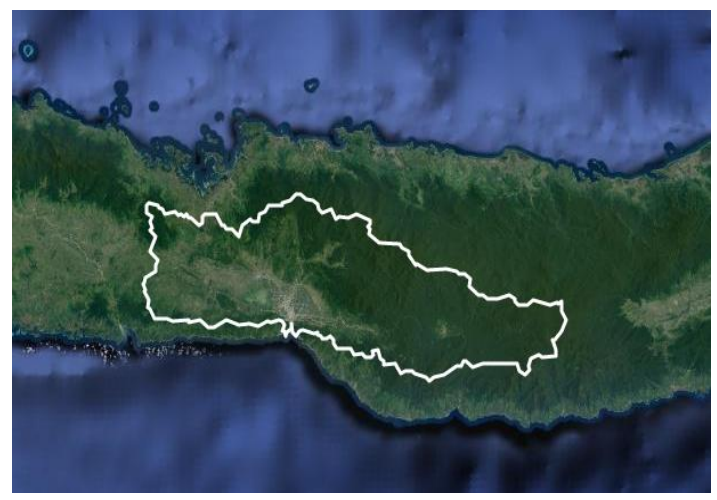

bergantung pada curah hujan.

bagus(Kurnia, Muharsyah, and Widiyanto 2020).

Google Earth Engine adalah layanan pemrosesan geospasial. Dengan GEE dapat melakukan pemrosesan geospasial dalam skala besar, yang didukung oleh Google Cloud Platform (Developers Google 2008). Sejumlah kelebihan GEE yang dapat mengolah data dalam skala besar ini membuat terobosan baru dalam sejumlah penelitian termasuk penelitian mengenai data curah hujan secara temporal/time series. Penggunaan GEE sangat membantu dalam analisis spasial temporal pada wilayah dengan stasiun curah hujan yang sedikit (Zeng et al. n.d.).

\section{METODOLOGI}

\section{Lokasi Penelitian}

Lokasi penelitian ini berada di DAS

Limboto Bone Bolango Provinsi Gorontalo. Lokasi penelitian disajikan pada Gambar 1.

\section{Data}

1. Curah hujan dari TRMM 3B43: Monthly Precipitation Estimates (TRMM/3B43V7) dan ERA5-Land monthly averaged - ECMWF climate reanalysis (ECMWF/ERA5_LAND/MONTHL).

2. Batas wilayah DAS Limboto Bone Bolango

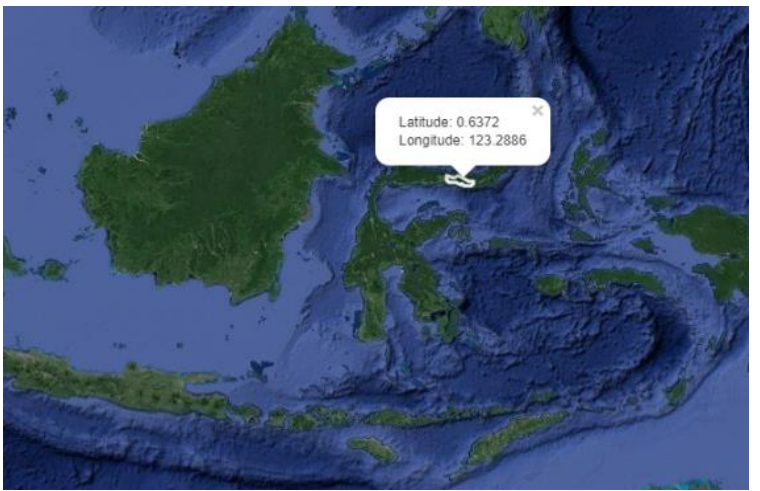

Gambar 1. Lokasi Penelitian 


\section{Pengolahan Data}

Pengolahan data menggunakan Google Earth Engine dan Google Colab. Data TRMM/3B43V7 dan data ECMWF/ERA5_LAND/MONTHLY diolah menjadi data time series curah hujan wilayah DAS Limboto Bone Bolango. Hasil pengolahan data tersebut digunakan untuk melihat pola hujan tiap hari dalam satu tahun (DOY). Padi Sawah banyak bergantung pada pengairan, sehingga penentuan awal musim tanam sama dengan awal musim penghujan.

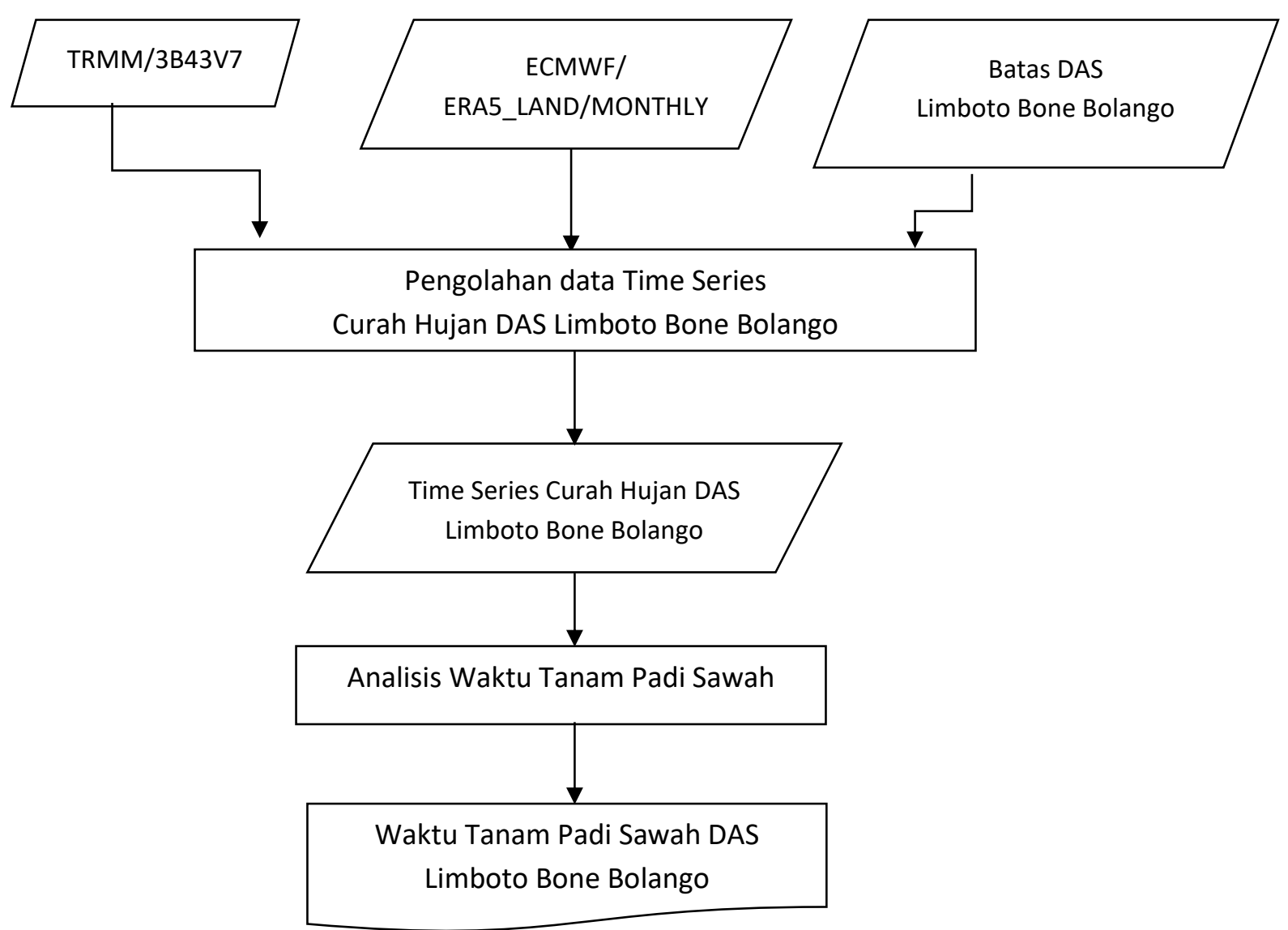

Gambar 2. Diagram Alir Penelitian

\section{HASIL DAN PEMBAHASAN}

Hasil pengolahan data time series curah hujan TRMM/3B43V7 dan ECMWF/ERA5_LAND/MONTHLY

(Gambar 3 dan Gambar 4). Awal musim tanam padi sawah adalah pada saat awal musim hujan. Berdasarkan time series median curah hujan dari data TRMM/3B43V7
ECMWF/ERA5_LAND/MONTHLY grafik curah hujan naik pada bulan Februari (DOY > 60) dan Oktober (DOY > 273). Berdasarkan hal tersebut rata-rata awal musim hujan dan sekaligus musim tanam padi sawah pada DAS Limboto Bone Bolango adalah pada bulan Februari dan Oktober. Tidak disarankan menanam pada bulan Juli hingga Agustus (DOY 181 $-244)$. 

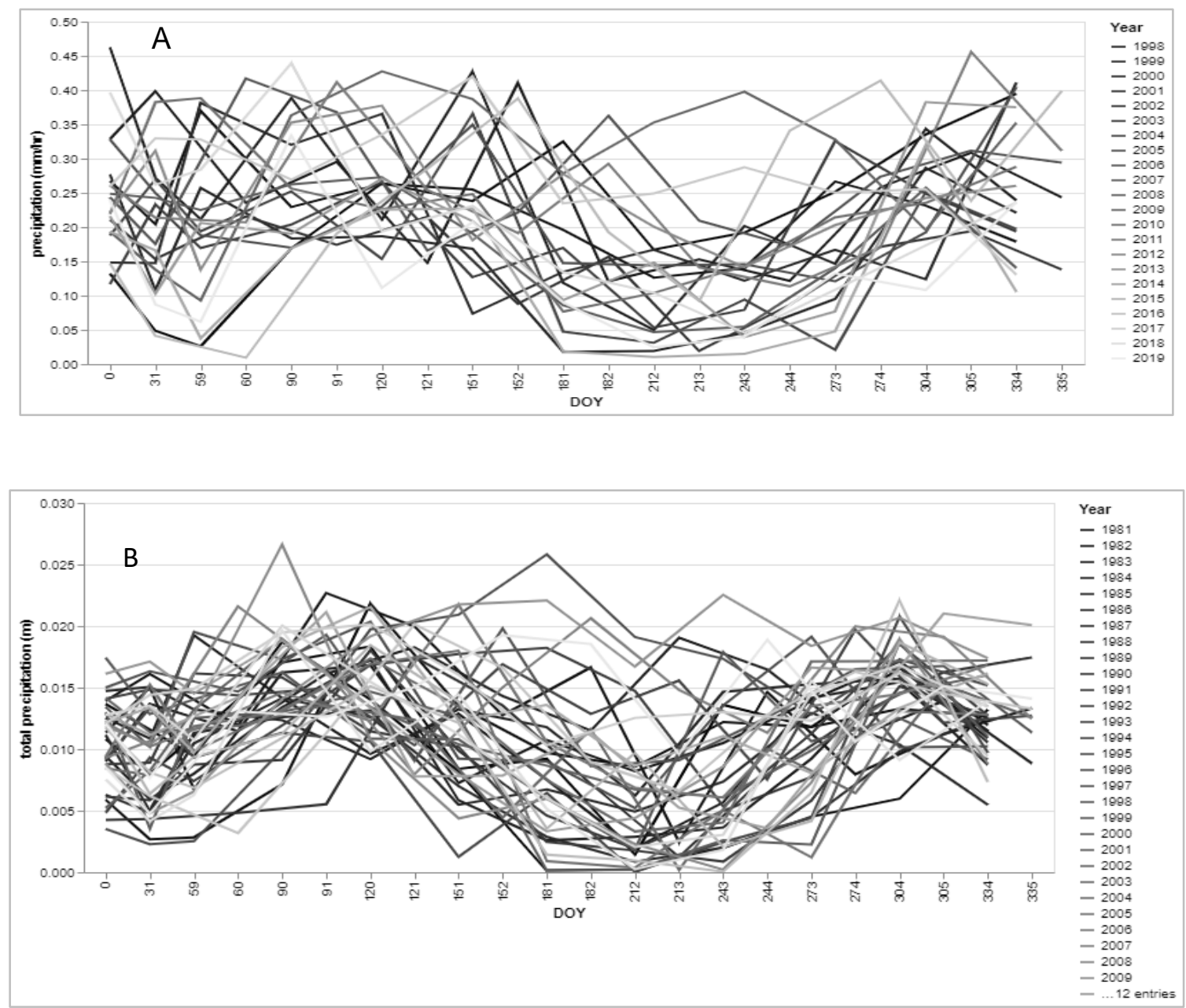

Gambar 3. Time Series Curah Hujan data TRMM/3B43V7 (A) dan ECMWF/ERA5_LAND/MONTHLY (B)

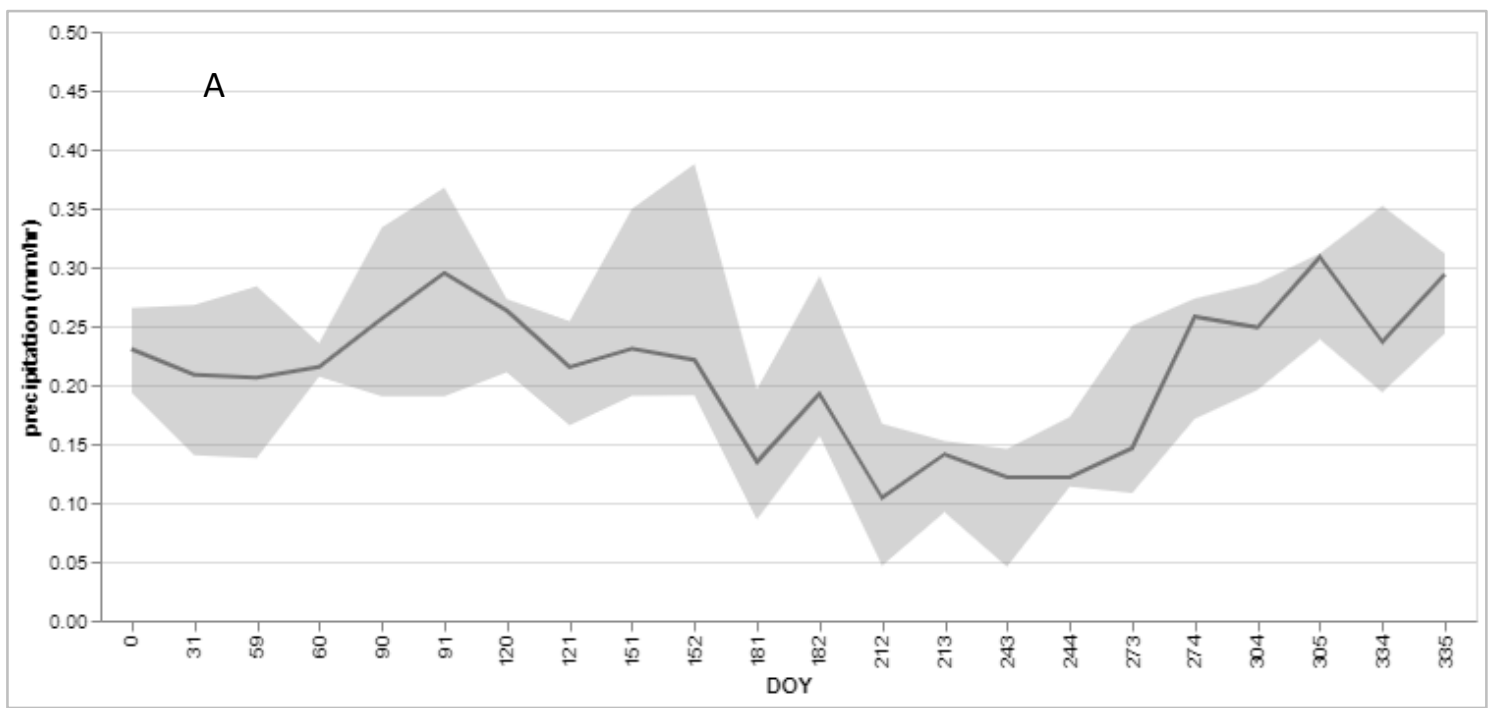




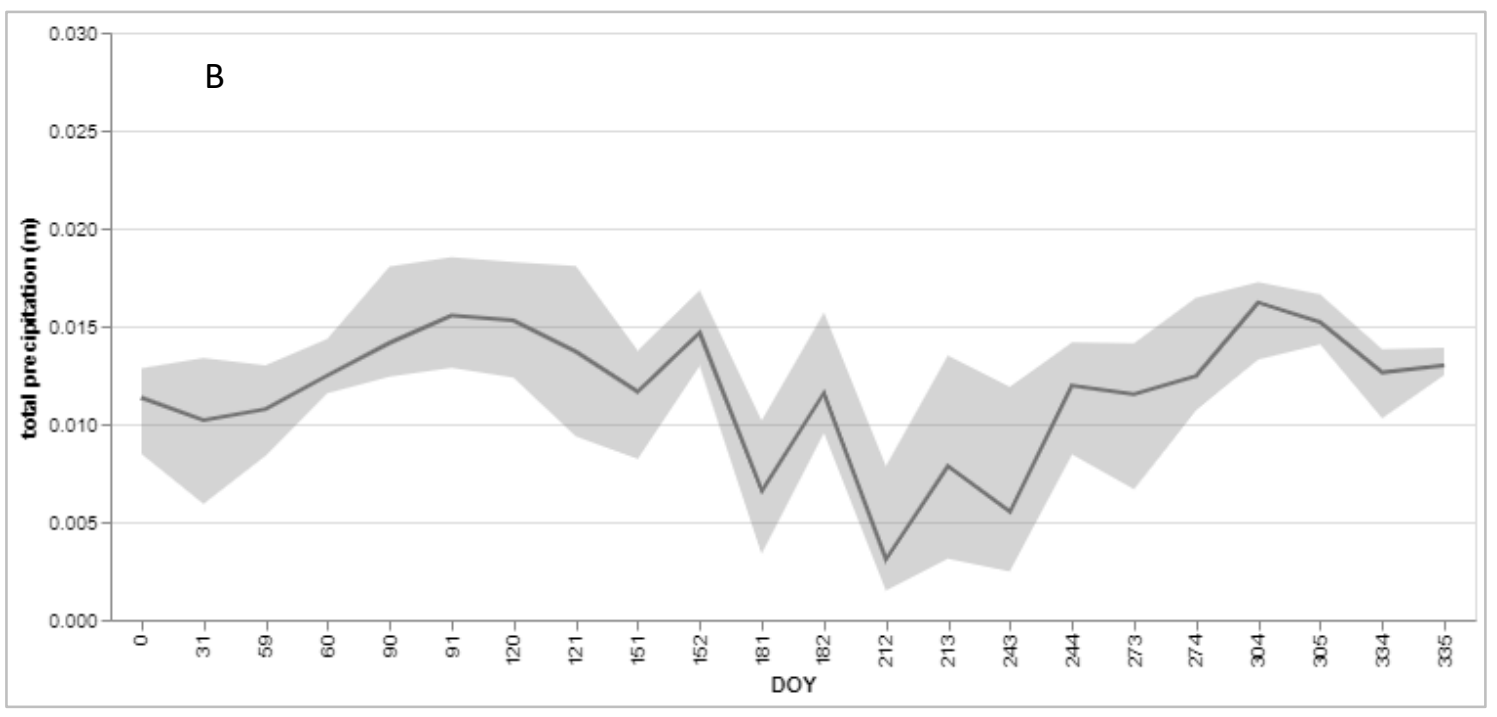

Gambar 4. Time Series Median Curah Hujan data TRMM/3B43V7 (A) dan ECMWF/ERA5_LAND/MONTHLY (B)

\section{KESIMPULAN}

Penentuan awal musim tanam padi sawah yang tepat dinilai dapat meminimalisir kegagalan panen. Awal musim tanam padi sawah sebaiknya pada saat awal musim penghujan hal ini bertujuan memungkinkan padi mendapatkan pengairan yang cukup pada fase vegetatif. Berdasarkan hasil penelitian ini awal musim hujan adalah pada bulan Februari dan Oktober, sehingga disarankan Petani memulai musim tanam pada bulan-bulan tersebut.

Penelitian ini fokus pada data time series curah hujan dari data RMM/3B43V7 dan ECMWF/ERA5_LAND/MONTHLY sehingga diharapkan penelitian lebih lanjut menggunakan data stasiun curah hujan. Penentuan musim tanam pada penelitian ini bersifat statis, sehingga diharapkan adanya penelitian yang dapat menentukan musim tanam secara dinamis berdasarkan curah hujan harian.

\section{DAFTAR PUSTAKA}

Dasanto, Bambang Dwi, Rizaldi Boer, Bambang Pramudya, Yuli Suharnoto, Departemen Geofisika, Fakultas Matematika, Institut Pertanian Bogor, Kampus Dramaga, Departemen Teknik, Fakultas Teknologi
Pertanian, Institut Pertanian Bogor, Departemen Teknik, Fakultas Teknologi Pertanian, and Institut Pertanian Bogor. 2014. "Evaluasi Curah Hujan TRMM Menggunakan Pendekatan Koreksi Bias Statistik." Evaluasi Curah Hujan TRMM Menggunakan Pendekatan Koreksi Bias Statistik 38(1):15-24.

Developers Google. 2008. "Welcome to Google Earth." Google 397-416. Retrieved

(https://developers.google.com/earthengine).

Gunawan, Dodo. 2014. "Perbandingan Curah Hujan Bulanan Dari Data Pengamatan Permukaan, Satelit Trmm Dan Model Permukaan Noah." Jurnal Meteorologi Dan Geofisika 9(1):1-10.

Hariyanti, Kharmila S., Tania June, Yonny Koesmaryono, Rahmat Hidayat, and Aris Pramudia. 2019. "Penentuan Waktu Tanam Dan Kebutuhan Air Tanaman Padi, Jagung, Kedelai Dan Bawang Merah Di Provinsi Jawa Barat Dan Nusa Tenggara Timur Determination of Planting Time and Crop Water Requirements of Rice , Maize, Soybean and Shallot in West Java and East." Jurnal Tanah Dan Iklim 43(1):83-92.

Jayanti, Kamelia Dwi, and Ita Mowidu. 2014. "Perkiraan Waktu Tanam Padi Sawah Tadah Hujan Di Desa Silanca 
Tahun 2015 Dengan Menggunakan Model Thomas-Fiering." Jurnal AgroPet Vol. 11 No:74.

Kurnia, Wenas Ganda, Robi Muharsyah, and Sofian Widiyanto. 2020. "Performa Koreksi Bias Prakiraan Curah Hujan Model European Centre Medium Weather Forecast ( ECMWF ) Di Sulawesi." Buletin GAW Bariri (BGB) 1(2):77-86.

Surmaini, Elza, Tri Wahyu Hadi, Kasdi Subagyono, and M. Ridho Syahputra. 2020. "Integrasi Prediksi Musim Dengan Model Simulasi Tanaman Untuk Penentuan Waktu Tanam Padi." Jurnal Tanah Dan Iklim 42(2):99.

Surmaini, Elza, and Haris Syahbuddin. 2016. "Kriteria Awal Musim Tanam: Tinjauan Prediksi Waktu Tanam Padi Di Indonesia." Jurnal Penelitian Dan Pengembangan Pertanian 35(2):47.

Syaifullah, M. Djazim. 2014. "Validasi Data Trmm Terhadap Data Curah Hujan Aktual Di Tiga Das Di Indonesia." Jurnal Meteorologi Dan Geofisika 15(2):109-18.

Zeng, Hongwei, Bingfang Wu, Ning Zhang, Fuyou Tian, and Elijah Phiri. n.d. "Spatiotemporal Analysis of Precipitation in the Sparsely Gauged Zambezi River Basin Using Remote Sensing and Google Earth Engine." 